\title{
Thermal Properties of DO Run IIB Silicon Detector Staves
}

\author{
Giobatta Lanfranco and James Fast \\ Fermi National Accelerator Laboratory \\ Particle Physics Division /Mechanical Dep. - Silicon Engineering Group \\ e-mail: giobatta@fnal.gov,jfast@fnal.gov
}

14 June 2001

\section{Abstract}

A proposed stave design for the D0 Run IIb silicon tracker outer layers featuring central cooling channels and hybrid substrates mounted directly to the silicon sensor surfaces is evaluated for heat transfer characteristics and thermal deflections. In order to control leakage current noise in the silicon it is necessary to maintain the silicon in Layer $2(\mathrm{R} \sim 100 \mathrm{~mm})$ at or below $+5 \mathrm{C}$. The current cooling system using $30 \%$ ethylene glycol in water can deliver coolant to the inlet of the silicon tracker at a temperature of $-8 \mathrm{C}$ to $-10 \mathrm{C}$. This paper also investigates some alternative coolant options for Run IIB. While these are not required for the outer layers of silicon, they may be needed for L0, which sits at $\mathrm{R} \sim 15 \mathrm{~mm}$. In this case the silicon must be kept at or below $-5 \mathrm{C}$, very near the lower limit for delivery of $30 \%$ glycol/water coolant. However, for the inner layers the electronics will be mounted independently from the silicon so the local heat flux is greatly reduced. This paper does not consider the cooling issues for the inner layers.

\section{The Stave Design}

The stave is constructed from $200 \mathrm{~mm}$ long ladders consisting of two silicon sensors, $37.2 \mathrm{~mm}$ wide by $100 \mathrm{~mm}$ long, glued together end-to-end with a hybrid, $35 \mathrm{~mm}$ wide and $60 \mathrm{~mm}$ long, glued to the silicon, centered on the sensor to sensor joint. Six of these ladder structures are joined end-to-end to form a $1.2 \mathrm{~m}$ long chain and two chains are attached to opposite sides of the stave core and cooling lines. Each hybrid has 10 SVX chips mounted on it for a total heat load of $5 \mathrm{~W}$ per hybrid. Figure 1 shows a cross-section of the stave. Table 1 summarizes the stave constituent materials, their thickness and their thermal conductivities. 
Fermi National Accelerator Laboratory

Giobatta Lanfranco Silicon Engineering Group - Mechanical Dep.

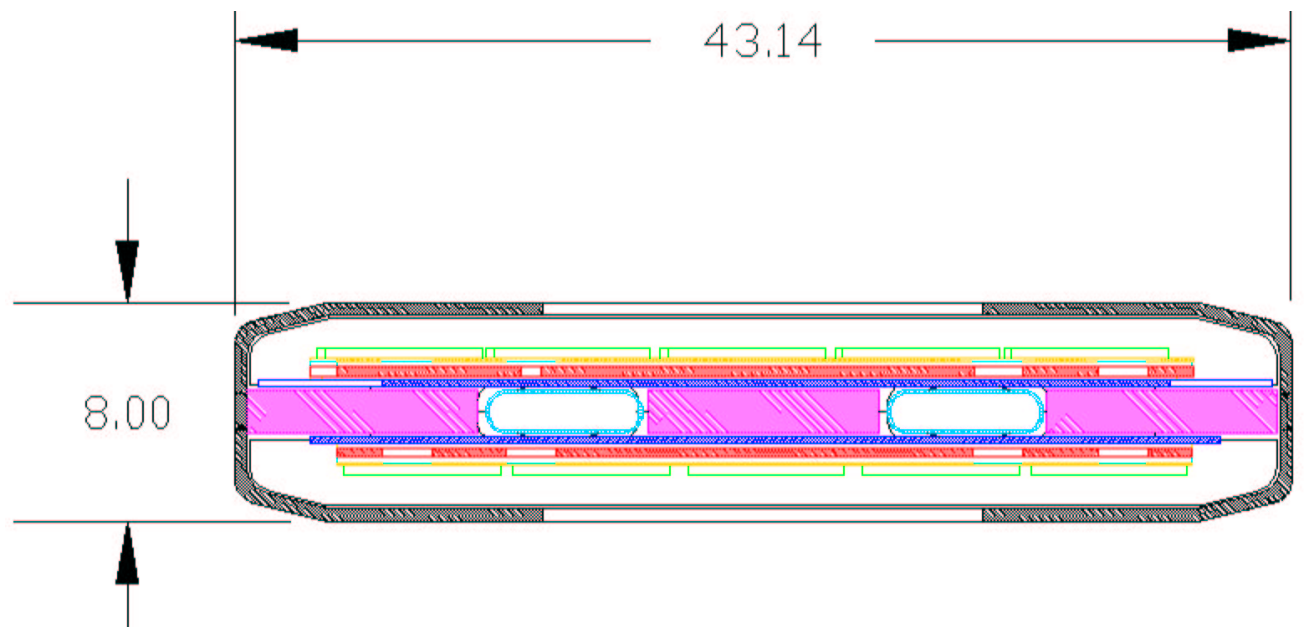

Figure 1-The stave cross section

\begin{tabular}{ccccc}
\hline Component & material & $\begin{array}{c}\text { Thickness } \\
{[\mu \mathrm{m}]}\end{array}$ & $\begin{array}{c}\text { Thermal } \\
\text { conductivity [W/mk] }\end{array}$ & Color in Figure 1 \\
\hline Support Shell & $\begin{array}{c}\text { Carbon Fiber } \\
\text { K139 }\end{array}$ & 500 & $\begin{array}{c}25-80 \text { in-plane } \\
0.4 \text { inter-plane }\end{array}$ & black \\
\hline Sensor & Silicon & 380 & 124 & blue \\
\hline Chip & Silicon & 300 & 124 & green \\
\hline Glue & Epoxy & 50 & 1 & white \\
\hline $\begin{array}{c}\text { Tubing type 1 } \\
\text { Tubing type 2 }\end{array}$ & Al 1100 & 100 & 222 & cyan \\
\hline PEEK & Kapton & 100 & 0.25 & gold \\
\hline $\begin{array}{c}\text { Substrate } \\
\text { Heat spreader } \\
\text { Type 1 }\end{array}$ & BeO & 100 & 0.2 & red \\
\hline $\begin{array}{c}\text { Heat spreader } \\
\text { Type 2 }\end{array}$ & Carbon Fiber \\
\hline $\begin{array}{c}\text { Heat spreader } \\
\text { Kype 3 }\end{array}$ & Kapton & 100 & $\begin{array}{c}150-300 \text { in-plane } \\
0.3 \text { inter-plane }\end{array}$ & not shown \\
\hline
\end{tabular}

Table 1-Thermal conductivities and thickness of the stave constituent materials 
Fermi National Accelerator Laboratory

Giobatta Lanfranco Silicon Engineering Group - Mechanical Dep.

\section{The Finite Element Model}

The governing law of heat conduction is the Laplace equation, a second-order ordinary differential equation. For one-dimensional, steady state conduction the temperature distribution can't be determined unless two boundary conditions are specified.

The heat generated in the chip sets the first condition. The chip size used in the model is $11.6 \mathrm{~mm}$ long by $6.4 \mathrm{~mm}$ wide, each chip dissipating $0.5 \mathrm{~W}$. The heat generation is not homogeneously distributed: $25 \%$ of the power is dissipated along $2 \mathrm{~mm}$ wide strips at each end of the $11.6 \mathrm{~mm}$ dimension, while the remaining $50 \%$ is dissipated in the central region.

The second condition is set through the convection at the inner wall of the cooling pipe. The second part of this paper contains a study of some of the feasible coolants, which will let us predict the achievable average bulk temperature in the pipe along with the film coefficient. For simplicity, the problem can be split into two parts, with the finite element analysis providing the thermal gradient along the stave and the theoretical analysis of the coolant fixing the temperature drop from the tube wall to the bulk fluid. In the finite element model the bulk temperature of the coolant has been fixed at $-5{ }^{\circ} \mathrm{C}$ and a convection film coefficient $\mathrm{h}_{\mathrm{c}}=2000 \mathrm{~W} / \mathrm{m}^{2} \mathrm{~K}$ is used.

To reduce the calculations required, observing the longitudinal symmetry, only one quarter of the stave has been considered. This is reflected in the pictures shown (Figure 3 through Figure 8).

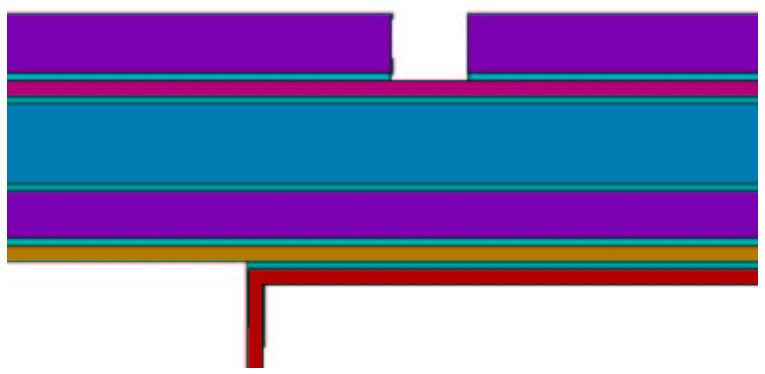

Figure 2 - Detail of the stave material stuck-up. Colour guide: violet - Silicon (chip, detector); pink - kapton (hdi); azure beryllia oxide (substrate); orange -TPG/K13D2U/Kapton layer; aqua-epoxy; red-PEEK( tubing)

\subsection{Finite Element Analysis Results}

Six different configurations have been studied. Aluminium tubing, although providing the best performance from a thermal standpoint, is subject to galvanic corrosion when in contact with carbon fiber as well as to the risk of erosion due to the ions in the coolant. These problems, together with a non 
Fermi National Accelerator Laboratory

Giobatta Lanfranco Silicon Engineering Group - Mechanical Dep.

optimal radiation length, make it necessary to investigate alternative materials. PEEK (Polyetheretherketone), even though it has a very low thermal conductivity, has none of the problems affecting aluminium, it is radiation hard and its low modulus of elasticity can be an advantage when the tube is coupled to the silicon sensors. Configurations 1 and 2 compare aluminium with PEEK tubing. An attempt to improve the poorer PEEK thermal performance is studied in configuration 3; even though a TPG (Thermal Pyrolytic Graphite) hybrid substrate is not viable because of the intrinsic manufacturing limitations, use of a higher thermal conductivity material in the hybrid substrate can effectively reduce the temperature in the detector.

Finally, configurations 4, 5 and 6 analyze the effect of an extra layer of TPG, high conductivity carbon fiber or Kapton added between the stave core (cooling lines) and the sensors. This layer would greatly aid stave assembly by making the core structure a mechanically stable sub-assembly prior to attachment of the silicon ladders. The better TPG performance may not justify the higher cost of the material and the lower mechanical performance when compared with the K13D2U laminate. The Kapton layer is considered for electrical insulation purposes. Its good results, even if apparently in contradiction with its low thermal conductivity, may be explained by its lower thickness together with the fact that in all the three configurations the conductivity of the materials through the plane are comparable and rather low.

\begin{tabular}{c|ccc}
\hline & Configuration & $\begin{array}{c}\mathbf{T}_{\mathbf{m a x}} \\
{\left[{ }^{\circ} \mathbf{C}\right]}\end{array}$ & $\begin{array}{c}\mathbf{T}_{\mathbf{m a x}} \\
{\left[{ }^{\circ} \mathbf{C}\right]}\end{array}$ \\
\hline 1 & Aluminium Tubing \\
\hline 2 & PEEK Tubing & 2.2 & -1.6 \\
\hline 3 & PEEK Tubing + TPG substrate & 4.5 & 0.8 \\
\hline 4 & PEEK Tubing with TPG layer & 4.0 & -0.7 \\
\hline 5 & PEEK Tubing with K13D2U layer & 5.2 & 0.2 \\
\hline 6 & PEEK Tubing with Kapton layer & 3.9 & -0.2 \\
\hline
\end{tabular}

Table 2 - Finite element configurations and maximum temperature on the SVX chips and in the silicon sensors. Unless specified, a BeO substrate is used. (* note that the Kapton layer is $50 \mu m$ thick, vs. $100 \mu m$ for the other materials) 
Fermi National Accelerator Laboratory

Giobatta Lanfranco Silicon Engineering Group - Mechanical Dep.

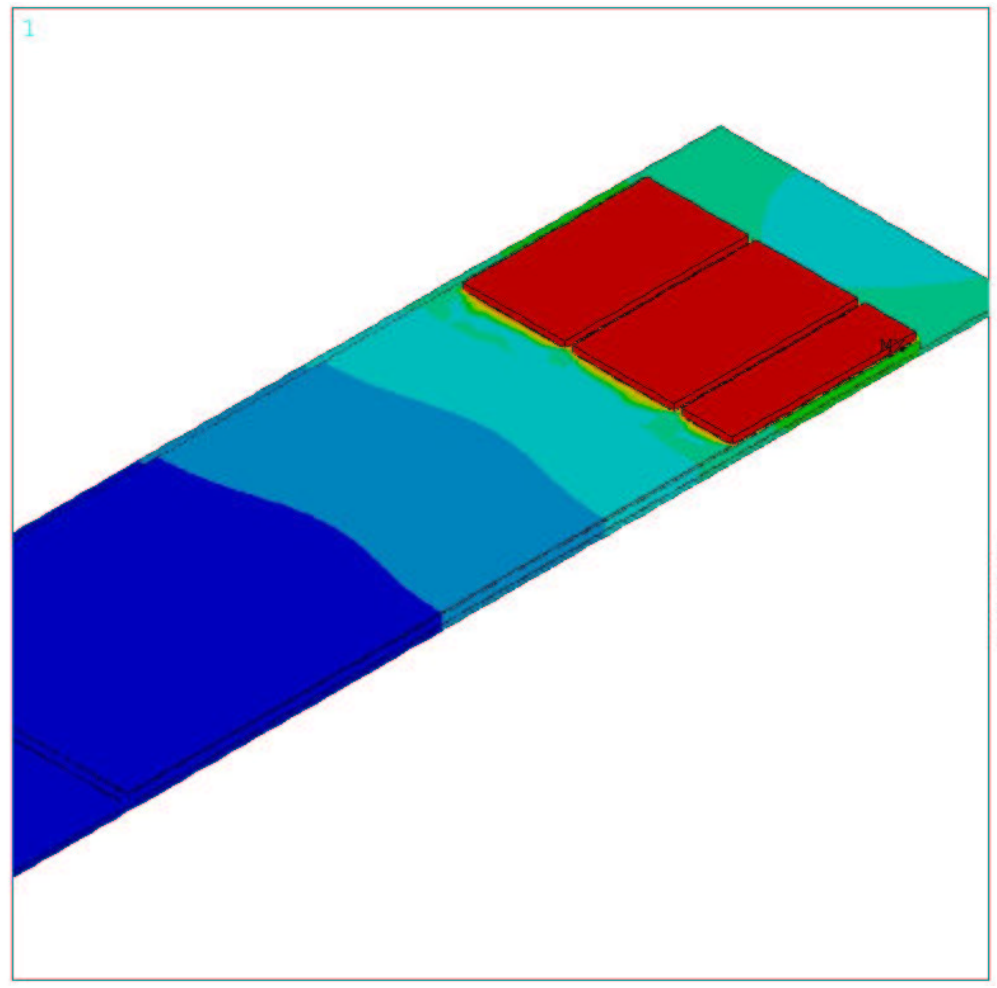

ANSYS 5.5 .1

MAR $28 \quad 2001$

$09: 28: 23$

NODAL SOLUTION

$\mathrm{STEP}=1$

SUB $=1$

TIME $=1$

TEMP

RSYS $=0$

PowerGraphics

EFACET $=1$

AVRES $=$ Mat

SMN $=-5$

SMX $=2.146$

$\mathrm{XV}=1$

$\mathrm{YV}=1$

$2 \mathrm{~V}=1$

$\star \mathrm{DI} \mathrm{ST}=21.788$

$\star \mathrm{XF}=22.674$

${ }^{\star} Y \mathrm{~F}=9.741$

$\star \mathrm{ZF}=36.576$

PRECISE HIDDEN

$-5$

$-4.206$

$-3.412$

$-2.618$

$-1.824$

$-1.03$

$-.235748$

.558278

1.352

2. 146

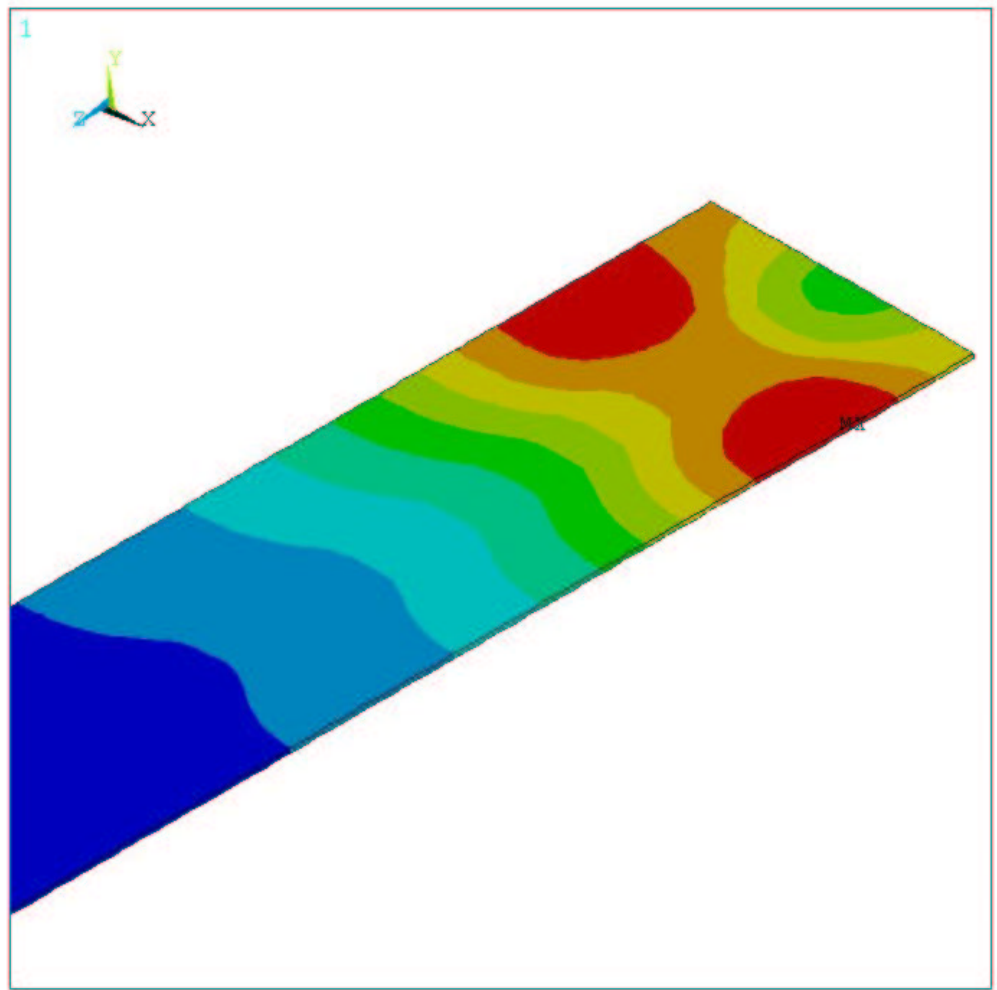

ANSYS 5.5 .1

MAR $28 \quad 2001$

$10: 40: 51$

NODAL SOLUTION

$\operatorname{STE} P=1$

SUB $=1$

TIME $=1$

TEMP

〈AVG)

RSYS $=0$

PowerGraphics

EFACET $=1$

AVRES $=$ Mat

SMN $=-5$

$\operatorname{SMX}=-1.573$

$\mathrm{xV}=1$

$\mathrm{YV}=1$

$\mathrm{ZV}=1$

*DIST $=24.604$

${ }^{*} \mathrm{XF}=21.486$

*YF $=11.058$

${ }^{*} \mathrm{ZF}=36.446$

PRECISE HIDDEN

$-5$

$-4.619$

$-4.238$

$-3.857$

$-3.477$

$-3.096$

$-2.715$

$-1.953$

$-1.573$

Figure 3 - Temperature distribution of the silicon ladder with aluminum cooling tubing. 
Fermi National Accelerator Laboratory

Giobatta Lanfranco Silicon Engineering Group - Mechanical Dep.

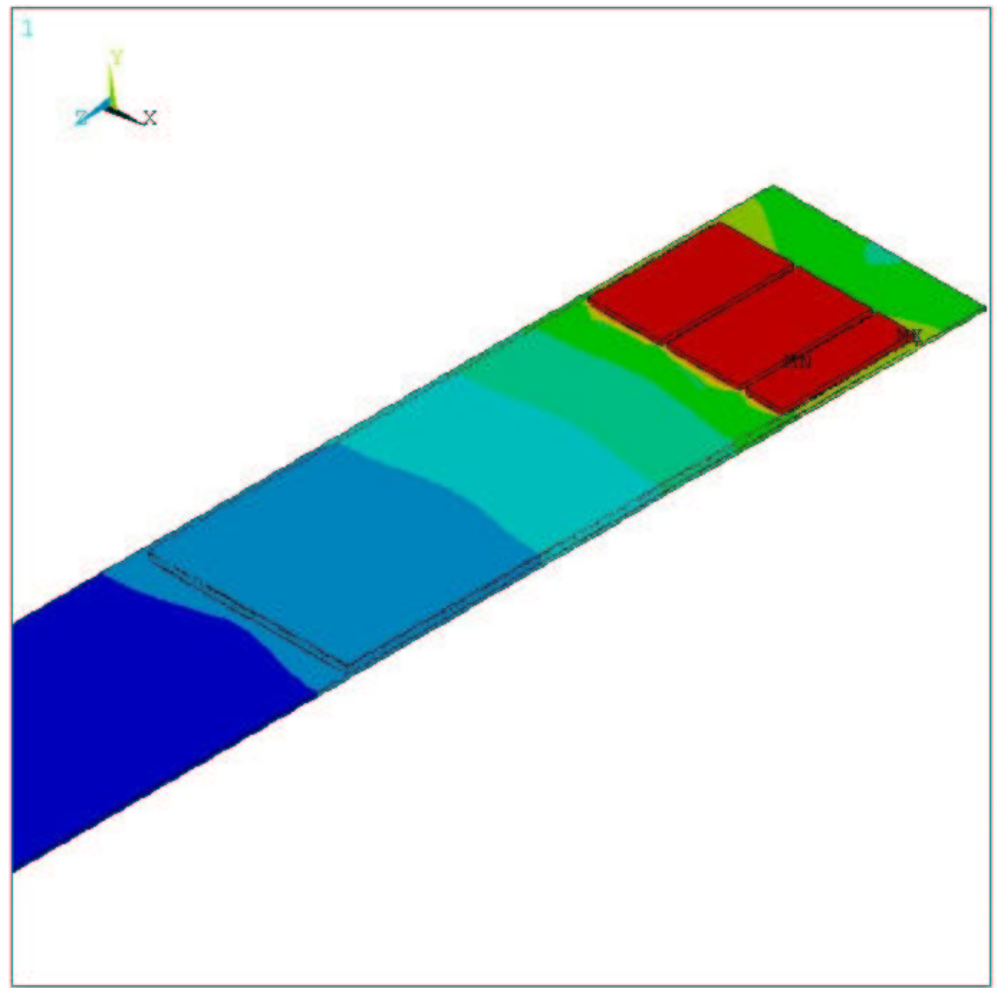

ANSYS 5.5.1

MAR $28 \quad 2001$

$10: 47: 49$

NODAL SOLUTION

$\mathrm{STEP}=1$

SUB $=1$

TIME $=1$

TEMP

(AVG)

RSYS $=0$

PowerGraphics

EFACET $=1$

AVRES $=$ Mat

SMN $=-5$

$\operatorname{SMX}=4.49$

$X V=1$

$Y V=1$

ZV $=1$

${ }^{\star} \mathrm{DIST}=30.397$

${ }^{*} \mathrm{XF}=18.849$

*YF $=7.378$

$\star \mathrm{ZF} \quad=42.762$

PRECISE HIDDEN

$-5$

$-4.18$

$-3.097$

$-2.013$

$-.929016$

.15479

1.239

2.322

2. 322
3.406

4.49

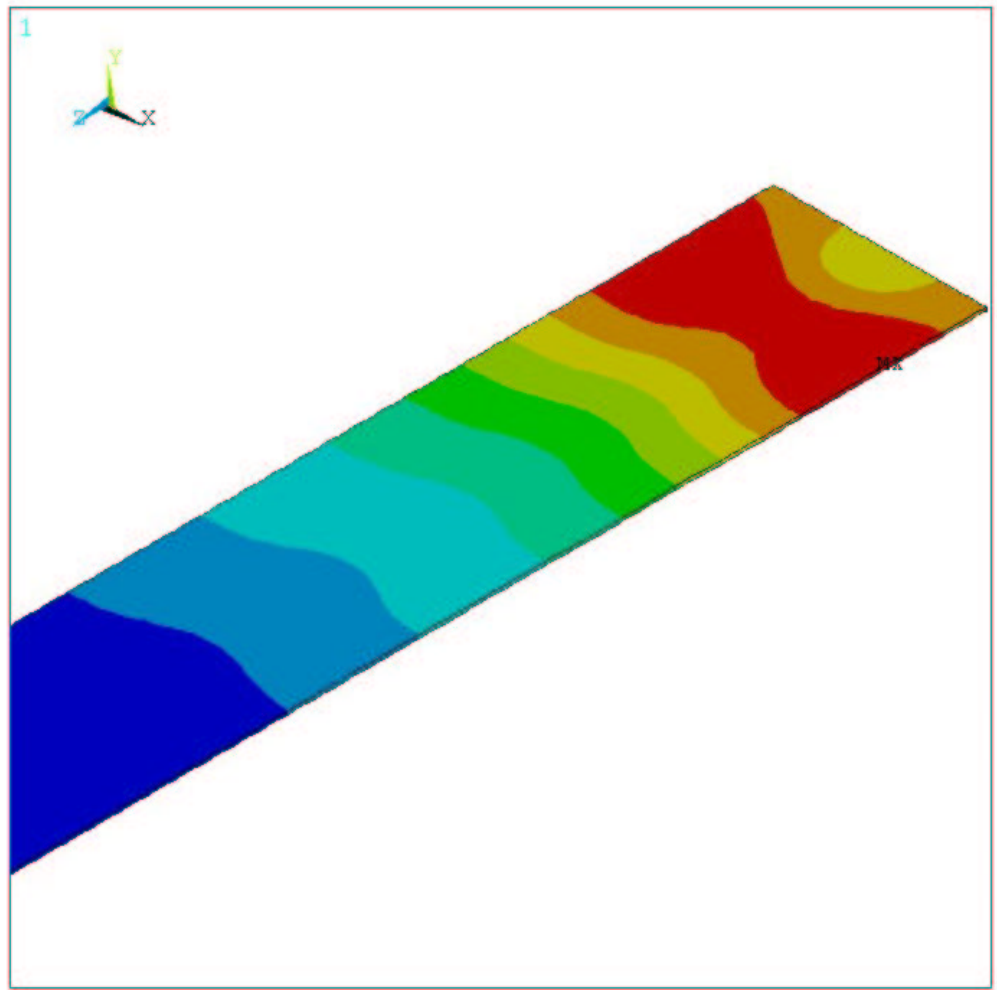

ANSYS 5.5 .1

MAR $28 \quad 2001$

$10: 49: 31$

NODAL SOLUTION

STEP $=1$

SUB $=1$

TIME $=1$

TEMP

RSYS $=0$

(AVG)

PowerGraphics

EFACET $=1$

AVRES $=$ Mat

SMN $=-4.996$

$\operatorname{SMX}=.797573$

$\mathrm{XV}=1$

$Y V=1$

$\mathrm{ZV}=1$

$\star \mathrm{DIST}=30.397$

$* X F=18.849$

$\star Y F=7.378$

$* \mathrm{ZF}=42.762$

PRECISE HIDDEN

$-4.996$

$-4.352$

$-3.708$

$-3.065$

$-2.421$

$-1.777$

$-1.134$

$-.489869$

.153852

.797573

Figure 4 - Temperature distribution of the silicon ladder with PEEK cooling tubing.

The upper plot shows the ladder with hybrid while the lower plot shows the temperature distribution in the silicon sensor. 
Fermi National Accelerator Laboratory

Giobatta Lanfranco Silicon Engineering Group - Mechanical Dep.

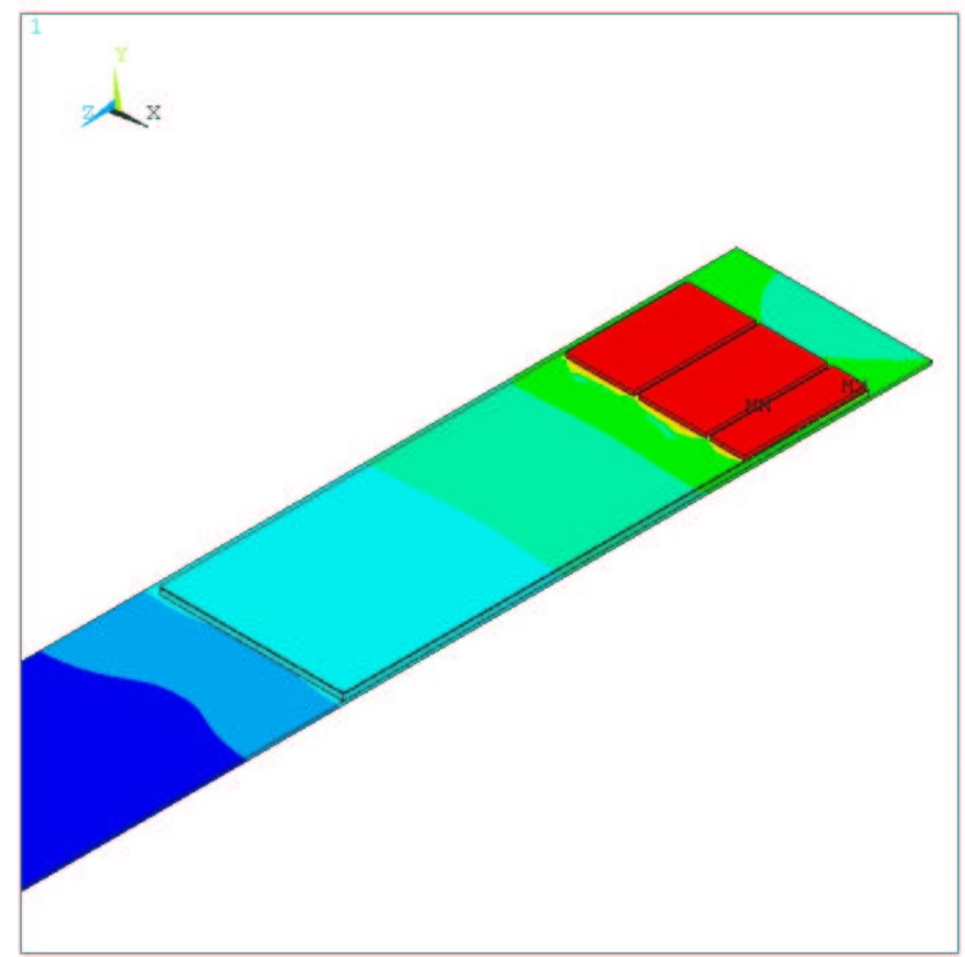

ANSYS 5.5 .1

MAY 222001

$13: 11: 47$

NODAL SOLUTION

$\mathrm{STEP}=1$

SUB $=1$

TIME $=1$

TEMP

(AVG)

RSYS $=0$

PowerGraphics

EFACET $=1$

AVRES $=$ Mat

$\mathrm{SMN}=-4.993$

$\operatorname{SMX}=3.441$

$\mathrm{XV}=1$

IV $=1$

$\mathrm{ZV}=1$

${ }^{*} \mathrm{DIST}=31.557$

${ }^{*} \mathrm{XF} \quad=17.599$

*YF $=10.26$

${ }^{*} \mathrm{ZF}=41.122$

Z-BUEFER

$-4.993$

$-4.24$

$-3.28$

$-2.32$

$-1.36$

$-.399338$

.56085

1. 521

2. 481

3. 441

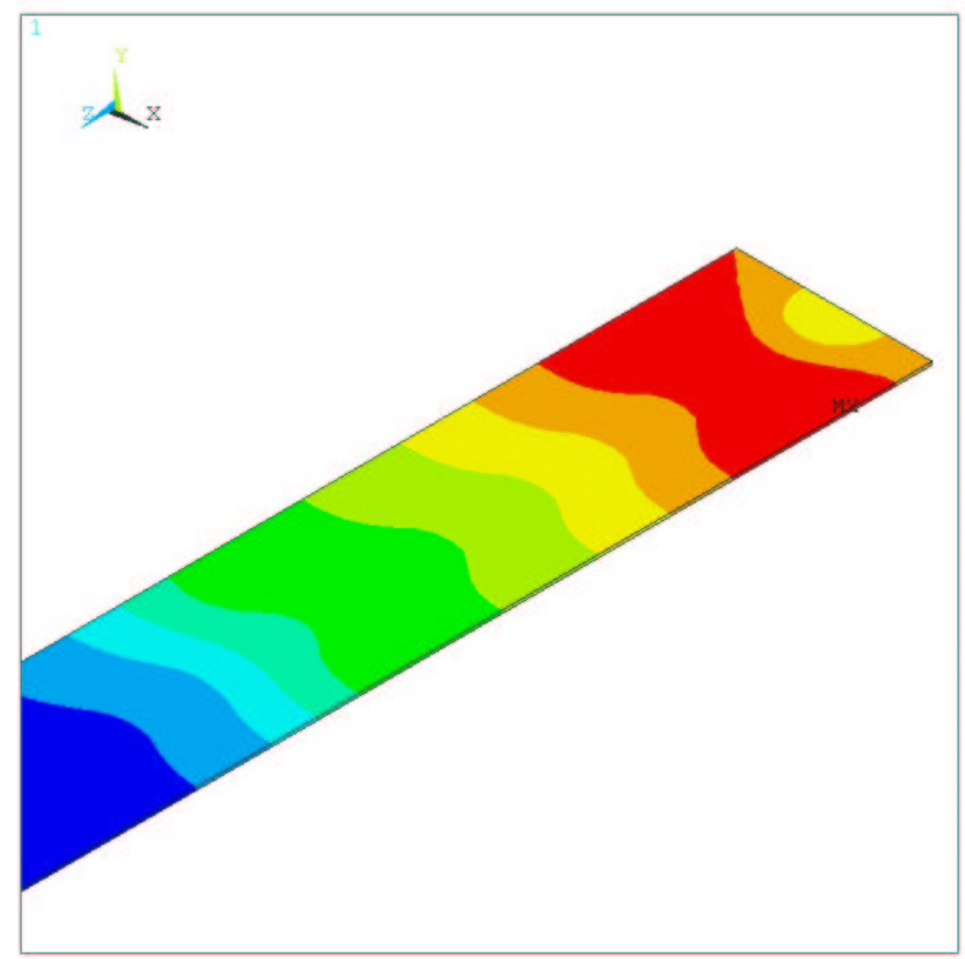

ANSYS 5.5 .1

MAY 222001

$13: 14: 55$

NODAL SOLUTION

STE $P=1$

SUB $=1$

TIME $=1$

TEMP

RSYS $=0$

(AVG)

PowerGraphics

EFACET $=1$

AVRES $=$ Mat

SMN $=-4.993$

SMX $=-.684222$

$\mathrm{XV}=1$

$Y V=1$

ZV $=1$

*DIST $=31.557$

$\star \mathrm{XF}=17.599$

*YF $=10.269$

$\mathrm{ZF}=41.122$

Z-BUEFER

$-4.993$

$-4.514$

$-4.035$

$-3.557$

$-3.078$

$-2.599$

$-2.12$

$-1.642$

$-1.163$

$-.684222$

Figure 5 - Temperature distribution of the silicon ladder with PEEK cooling tubing and TPG substrate.

The upper plot shows the ladder with hybrid while the lower plot shows the temperature distribution in the silicon sensor. 
Fermi National Accelerator Laboratory

Giobatta Lanfranco Silicon Engineering Group - Mechanical Dep.
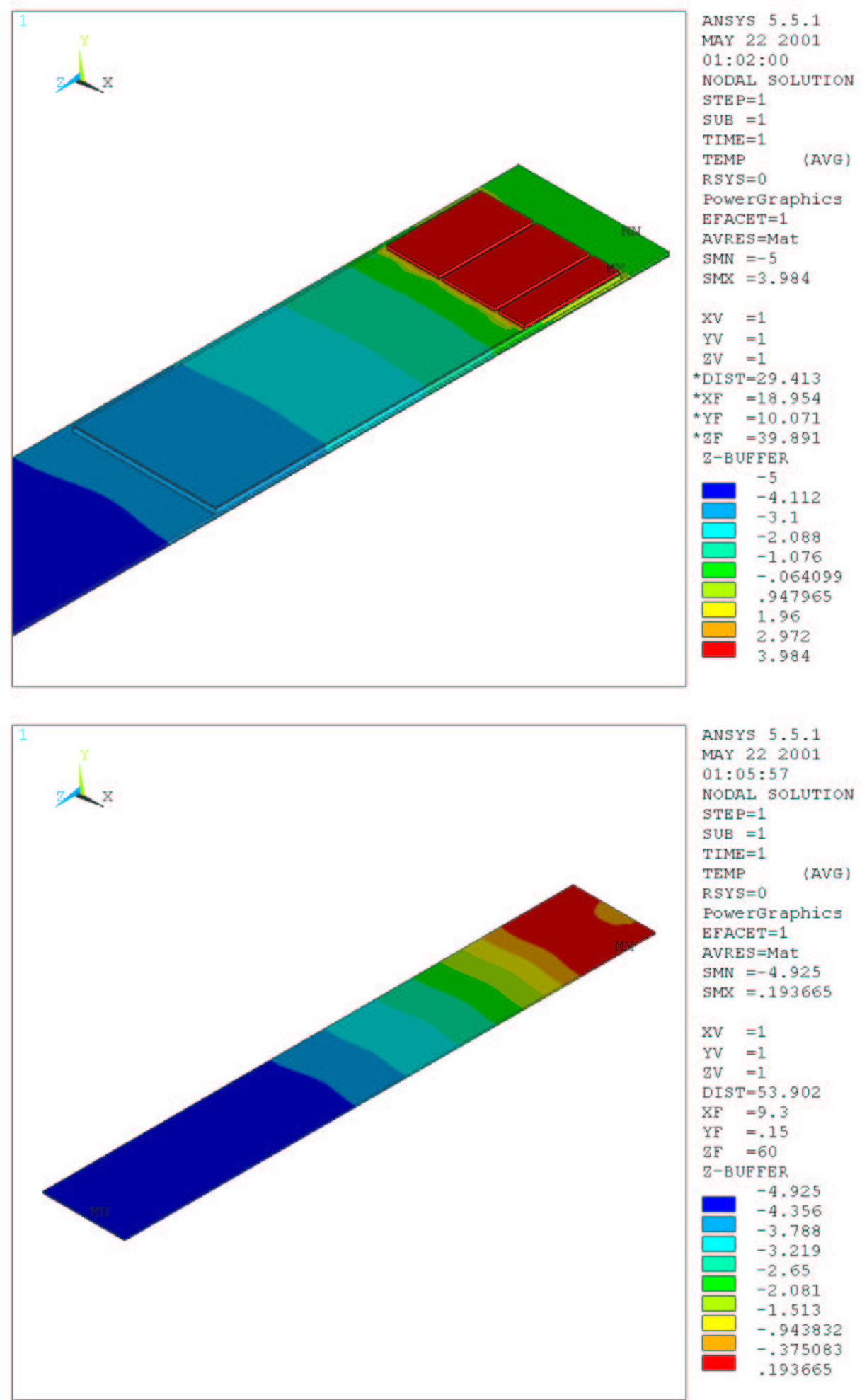
ANSYS 5.5 .1
MAY 222001
01:05:57
NODAL SOLUTION
$\mathrm{STEP}=1$
SUB $=1$
TIME = 1
TEMP
(AVG)
PowerGraphics EFACET $=1$
AVRE $S=$ Mat
SMN $=-4.925$
$\operatorname{SMX}=.193665$
$\mathrm{XV}=1$
$\mathrm{YV}=1$
$\mathrm{ZV}=1$
DIST $=53.902$
$\mathrm{XF}=9.3$
$\mathrm{YF}=.1$
$\mathrm{ZF}=60$
Z-BUEFER
$-4.925$
$-4.356$
$-3.788$
$-3.219$
$-2.65$
$-2.081$
$-1.513$
$-.943832$
$-.375083$
.193665

Figure 6 - Temperature distribution of the silicon detector with PEEK cooling tubing and TPG layer.

The upper plot shows the ladder with hybrid while the lower plot shows the temperature distribution in the silicon sensor. 
Fermi National Accelerator Laboratory

Giobatta Lanfranco Silicon Engineering Group - Mechanical Dep.
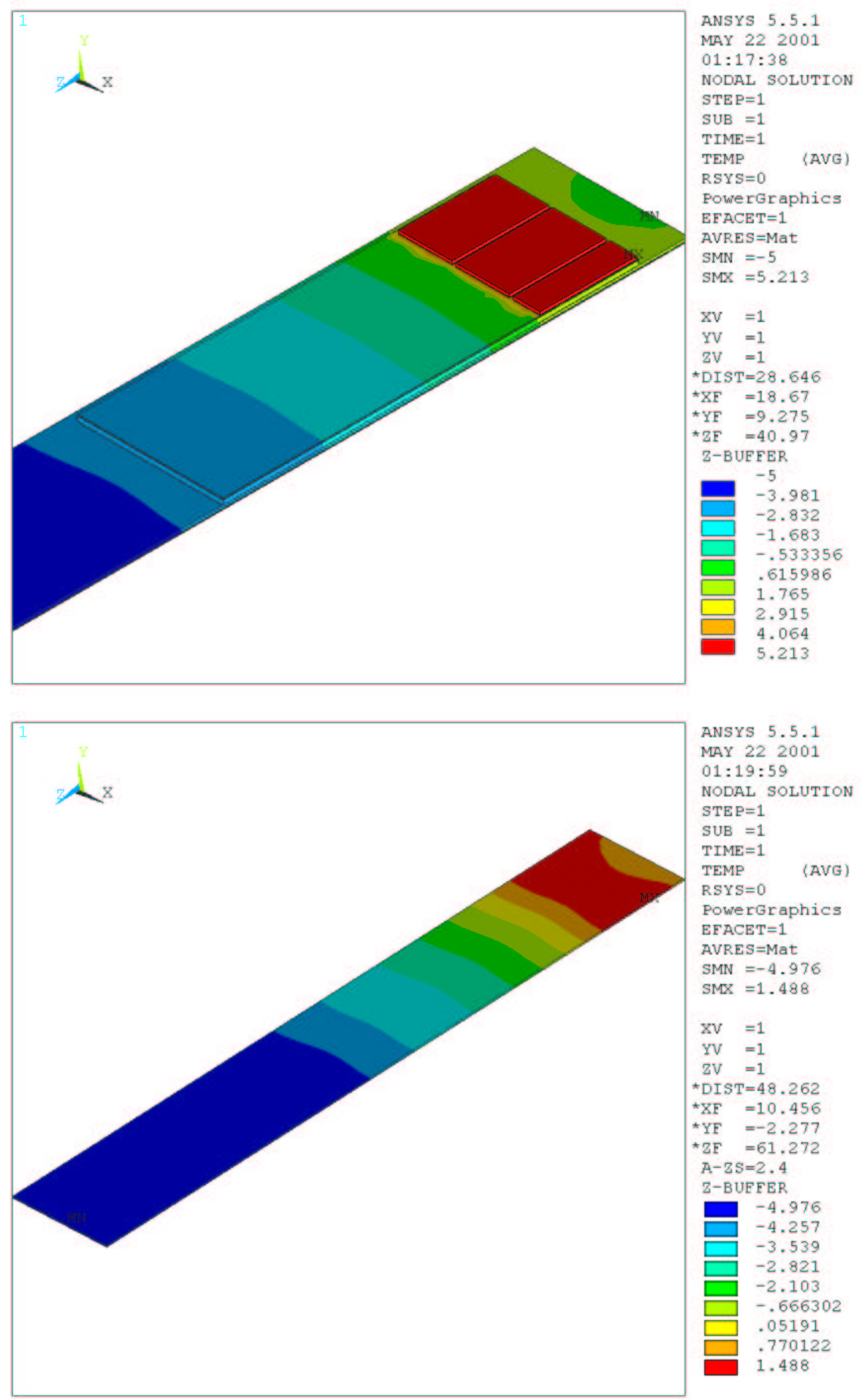

$$
\begin{aligned}
& \text { ANSYS 5.5.1 } \\
& \text { MAY } 222001 \\
& 01: 19: 59 \\
& \text { NODAL SOLUTION } \\
& \mathrm{STEP}=1 \\
& \text { SUB }=1 \\
& \text { TIME }=1 \\
& \text { TEMP } \\
& \text { RSYS }=0 \\
& \text { PowerGraphics } \\
& \text { EFACE T }=1 \\
& \text { AVRES }=\text { Mat } \\
& \text { SMN }=-4.976 \\
& \operatorname{SMX}=1.488 \\
& \mathrm{XV}=1 \\
& \mathrm{YV}=1 \\
& \mathrm{ZV}=1 \\
& { }^{*} \mathrm{DIST}=48.262 \\
& { }^{*} \mathrm{XF}=10.456 \\
& \begin{aligned}
* \mathrm{XF} & =10.456 \\
\star \mathrm{YF} & =-2.277
\end{aligned} \\
& \begin{aligned}
* \mathrm{YF} & =-2.277 \\
* \mathrm{ZF} & =61.272
\end{aligned} \\
& \mathrm{~A}-\mathrm{ZS}=2.4 \\
& \text { Z-BUEFER } \\
& -4.976 \\
& \begin{array}{l}
-4.976 \\
-4.257 \\
-3.539
\end{array} \\
& -3.539 \\
& -2.821 \\
& -2.103 \\
& -.666302 \\
& .05191 \\
& .770122
\end{aligned}
$$

Figure 7 - Temperature distribution of the silicon detector with PEEK cooling tubing and K13D2U layer.

The upper plot shows the ladder with hybrid while the lower plot shows the temperature distribution in the silicon sensor. 
Fermi National Accelerator Laboratory

Giobatta Lanfranco Silicon Engineering Group - Mechanical Dep.

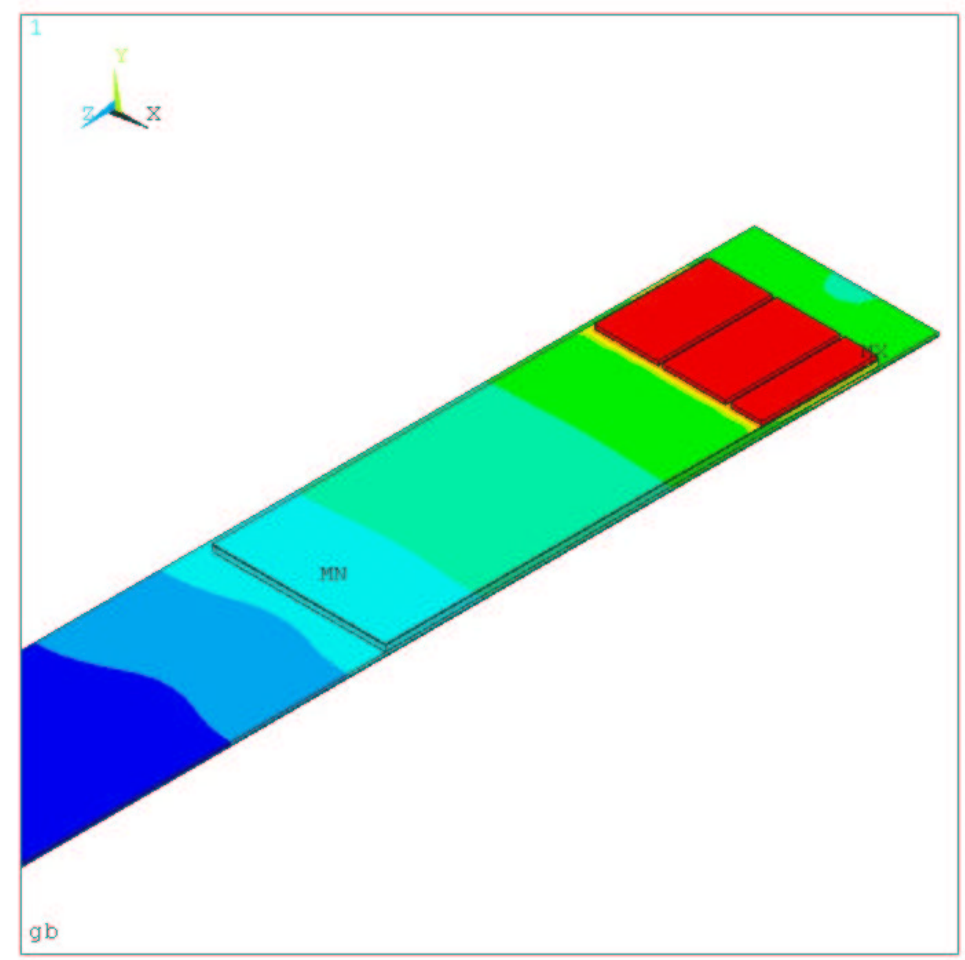

ANSYS 5.5 .1

MAY 222001

$15: 21: 13$

NODAL SOLUTION

STEP $=1$

SUB $=1$

TIME $=1$

TEMP

(AVG)

RSYS $=0$

PowerGraphics

EFACE $\mathrm{T}=1$

AVRES $=$ Mat

SMN $=-4.986$

$\operatorname{SMX}=3.882$

$\mathrm{XV}=1$

$Y V=1$

$2 \mathrm{~V}=1$

*DIST $=33.603$

$\star \mathrm{XF} \quad=16.991$

*YF $=8.095$

${ }^{*} \mathrm{ZF}=43.854$

Z-BUEFER

-4.986
-4.448

-3.407
-2.366

$-1.324$

$-.283195$

.758011

1.799

2.84

3.882

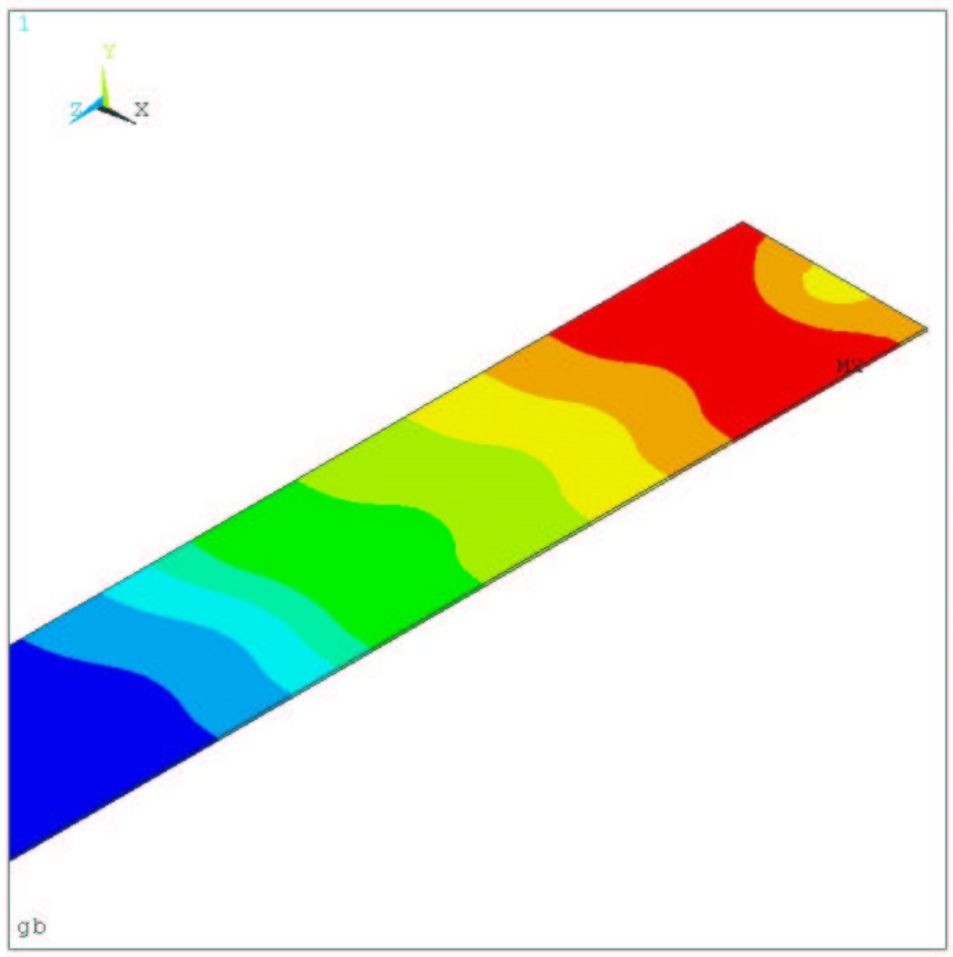

ANSYS 5.5 .1

MAY 222001

$15: 24: 22$

NODAL SOLUTION

$\mathrm{STEP}=1$

SUB $=1$

TIME = 1

TEMP

(AVG)

RSYS $=0$

PowerGraphics

EFACET $=1$

AVRES $=$ Mat

SMN $=-4.986$

SMX $=-.192178$

$\mathrm{XV}=1$

$\begin{array}{ll}\mathrm{YV} & =1 \\ \mathrm{ZV} & =1\end{array}$

DIST $=33.603$

$\star \mathrm{XF}=16.991$

*YF $=8.095$

${ }^{*} \mathrm{ZF}=43.854$

Z-BUFFER

$-4.986$

$-4.454$

$-3.921$

$-3.388$

$-2.856$

$-2.323$

$-1.79$

$-1.258$

$-.724864$

$-.192178$

Figure 8 - Temperature distribution of the silicon detector with PEEK cooling tubing and Kapton layer.

The upper plot shows the ladder with hybrid while the lower plot shows the temperature distribution in the silicon sensor. 
Fermi National Accelerator Laboratory

Giobatta Lanfranco Silicon Engineering Group - Mechanical Dep.

\section{Coolant Performance Analysis}

In order to evaluate and compare the performance offered by some of the most promising coolants nowadays widely adopted in cooling systems, the flow in a $1.2 \mathrm{~m}$ long pipe has been investigated. The pipe has a rectangular section and the outer dimensions are $6 \mathrm{~mm}$ by $2 \mathrm{~mm}$; the wall thickness is $100 \mu \mathrm{m}$. Given a power of $100 \mathrm{~W}$ to dissipate and given a flow bulk temperature at the entrance $\mathrm{T}_{\mathrm{b} 1}=$ $263 \mathrm{~K}$, two different conditions at the pipe exit have been set:

1. bulk temperature $\mathrm{T}_{\mathrm{b} 2}=265 \mathrm{~K}$;

2. pressure drop in the conduit $\Delta \mathrm{P}=6 \mathrm{psi}$

The cooling efficiency has been evaluated comparing the flow speed $U$ reached in the pipe, the mass rate $M$ required for the heat transfer, the average wall temperature $T_{\text {wall }}$, the film coefficient $h_{c}$ and the following dimensionless numbers:

- Reynolds number

$$
\operatorname{Re}=\frac{\rho U D_{H}}{\mu}
$$

where $\rho$ is the density, $U$ the velocity, $D_{H}$ the hydraulic diameter and $\mu$ the fluid viscosity. $\operatorname{Re}$ relates the viscous and inertial forces and determines the transition from laminar to turbulent flow. For flow in long ducts, where the entrance effects are not important, the laminar region ends around $\operatorname{Re}=2320$; from 2320 to 10000 a transition from laminar to turbulent flow takes place, where the viscous effects become more and more important (transitional regime); after that the turbulent flow is completely developed.

- Nusselt number

$$
\mathrm{Nu}=\frac{h_{c} D_{H}}{k}
$$

where $k$ is the thermal conductivity; $\mathrm{Nu}$, relating the film coefficient to the thermal conductivity of the fluid, gives an indication of which heat transfer phenomenon - convection versus conduction is prevailing in the fluid and provides a direct way to calculate $h_{c}$.

\section{- Prandtl number}

$$
\operatorname{Pr}=\frac{v}{\alpha}=\frac{c_{p} \mu}{k}
$$

where $v$ is the kinematic viscosity, $\alpha$ the thermal diffusivity and $c_{p}$ the specific heat. Since $v$ can be seen as the molecular diffusivity of momentum, Pr relates the temperature distribution to the 
velocity distribution. So the temperature gradient at the wall will be steeper in a fluid having a large Prandtl number at a specified Re. Consequently also the $\mathrm{Nu}$ will be larger and the convection will be more efficient.

The aforementioned quantities can be interpreted as follows:

- $\mathrm{U} \quad \Rightarrow$ excessively high values of the flow speed translate into high pressure drops and a higher probability of cavitation where the duct geometrical properties vary abruptly; vibrations in the pipe can also build up. On the other side however, low values of $U$ do not provide efficient convective heat transfer and lead to problems with removal of air bubbles at start-up. The Reynolds number is the key parameter for determining the right balance between these two conflicting requirements.

- $\mathrm{M} \quad \Rightarrow$ chiller size is proportional to mass flow.

- $\mathrm{T}_{\text {wall }} \Rightarrow$ lower values lead to lower working temperature for the chips and the silicon sensors

- $\mathrm{h}_{\mathrm{c}} \quad \Rightarrow$ higher values indicate more efficient convection ${ }^{1}$.

- $\operatorname{Re} \quad \Rightarrow$ since the convective mechanism relies on molecular mixing, and this is higher in turbulent flows than in the laminar regime (where the conduction is the predominant mechanism for the heat transfer to take place), relatively high values of Re are to be preferred.

- $\mathrm{Nu}, \mathrm{Pr} \Rightarrow$ high values of $\mathrm{Nu}$ as well as of $\operatorname{Pr}$ are to be pursued. That yields high film coefficients.

The coolants analyzed are:

- Dowcal 10, ethylene glycol based, Dow Chemical Corporation

- Dowcal N and Dowcal 20, propylene glycol based, Dow Chemical Corporation

- Syltherm XLT, Dow Chemical Corporation

- $3 \mathrm{M}$ Fluorinert $\mathrm{FC}-77, \mathrm{C}_{6} \mathrm{~F}_{14}(\mathrm{FC}-72)$ and $\mathrm{C}_{8} \mathrm{~F}_{18}$, perfluorocarbon liquids, 3M Corporation

\subsection{Results}

In Figure 9 through Figure 12 data are presented. It appears that the fluorinert $\mathrm{C}_{6} \mathrm{~F}_{14}$ exhibits the best performance. This, together with the good radiation hardness shown by this fluid (ref.1), makes it a good candidate for a cooling system.

\footnotetext{
${ }^{1}$ Higher heat transfer coefficients imply a larger fraction of fluid participating to the heat transfer, which means that less fluid mass is being circulated through the line uselessly.
} 
Fermi National Accelerator Laboratory

Giobatta Lanfranco Silicon Engineering Group - Mechanical Dep.

Finally, considering that the case where the pressure drop is set represents the most likely situation in our experiment. The values of $\mathrm{T}_{\text {wall }}=-5^{\circ} \mathrm{C}$ and $\mathrm{h}_{\mathrm{c}}=1855 \mathrm{~W} / \mathrm{m}^{2} \mathrm{~K}$ for $\mathrm{C}_{6} \mathrm{~F}_{14}$ are very close to what was assumed in the finite element model, confirming that the temperature distributions summarized in Table 2 are achievable.

$\mathrm{Tb} 2=-8^{\circ} \mathrm{C}$

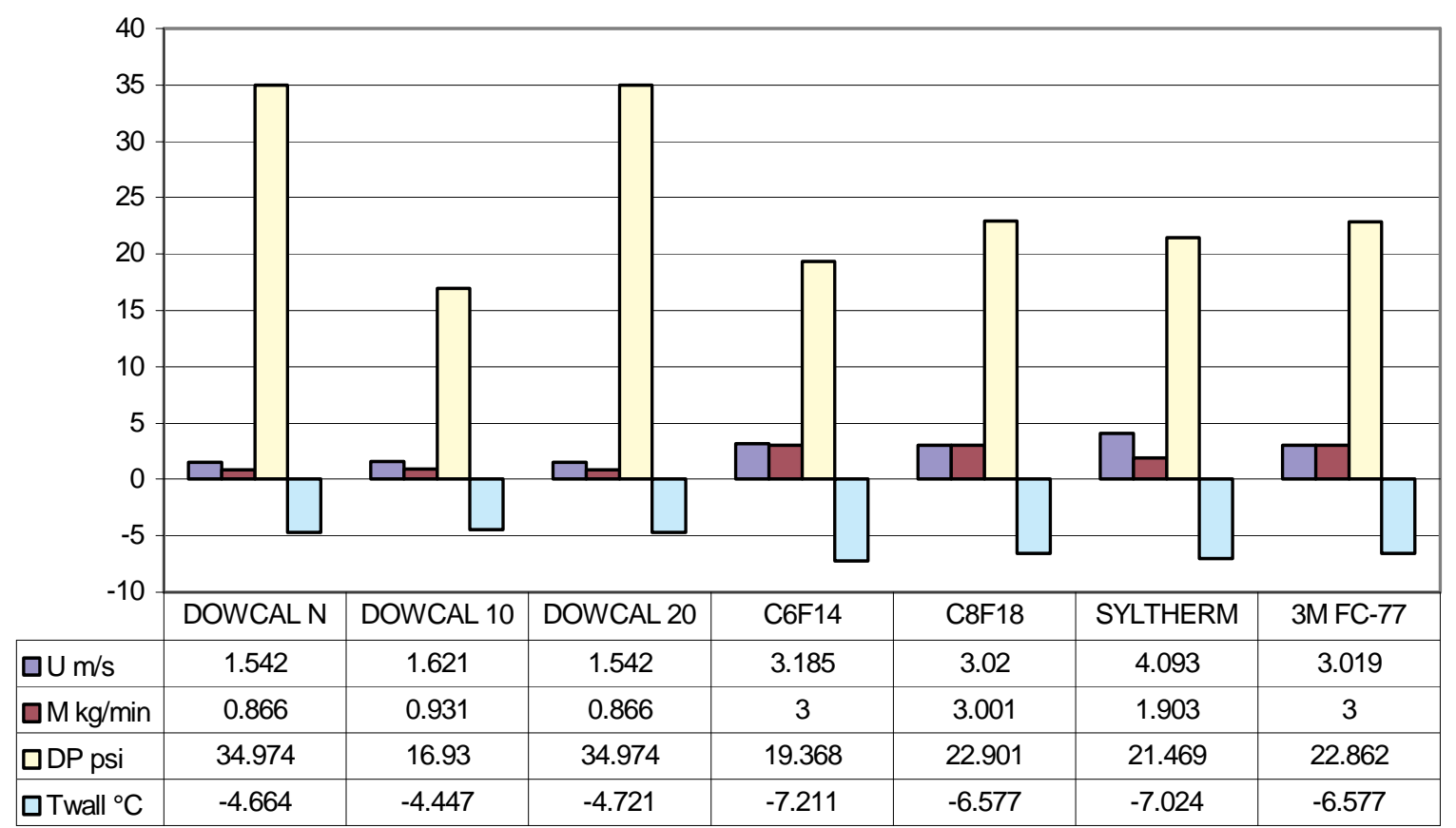

Figure 9 - Velocity $(U)$, mass rate $(M)$, pressure drop $(D P)$ and temperature at the wall (Twall) given the bulk temperature at the pipe exit. 
Fermi National Accelerator Laboratory

Giobatta Lanfranco Silicon Engineering Group - Mechanical Dep.

$\mathrm{Tb} 2=-8^{\circ} \mathrm{C}$

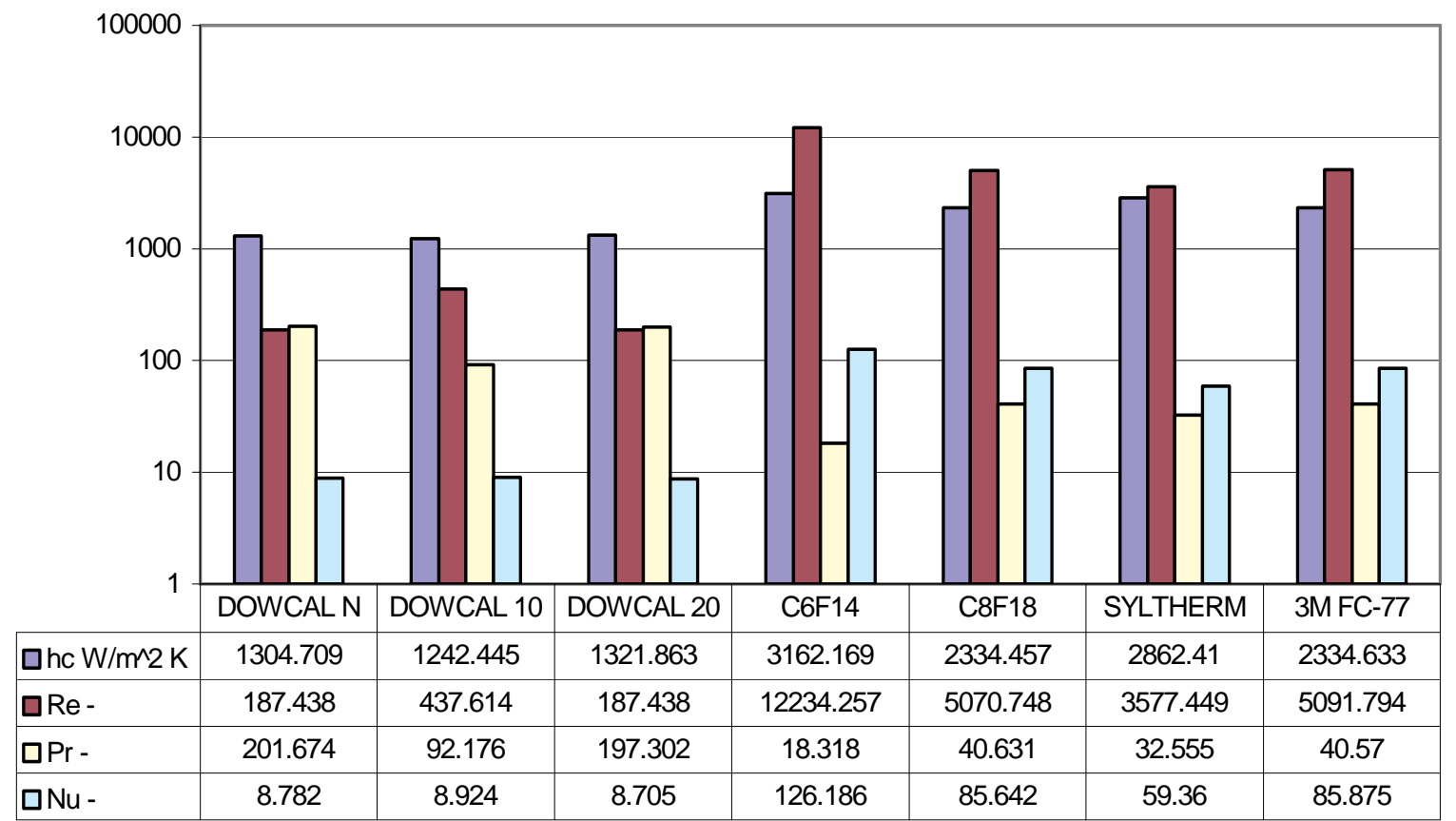

Figure 10 - Film coefficient (hc), Reynolds number (Re), Prandtl number (Pr) and Nusselt number (Nu) given the bulk temperature at the pipe exit.

$\mathrm{DP}=6 \mathrm{psi}$

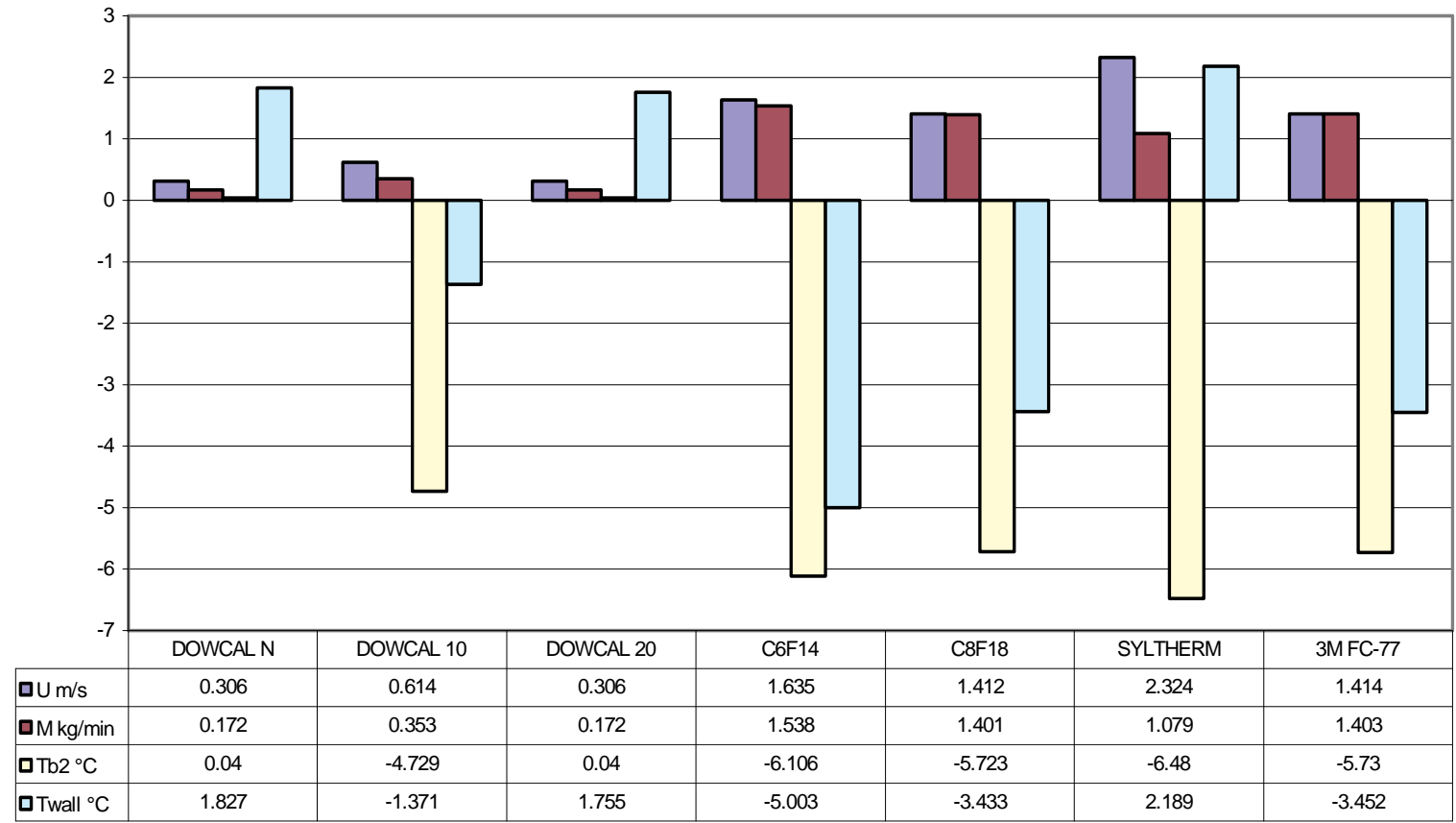

Figure 11 - Velocity $(U)$, mass rate $(M)$, exit bulk temperature (Tb2) and temperature at the wall (Twall) given the pressure drop along the pipe. 
Fermi National Accelerator Laboratory

Giobatta Lanfranco Silicon Engineering Group - Mechanical Dep.

$\mathrm{DP}=6 \mathrm{psi}$

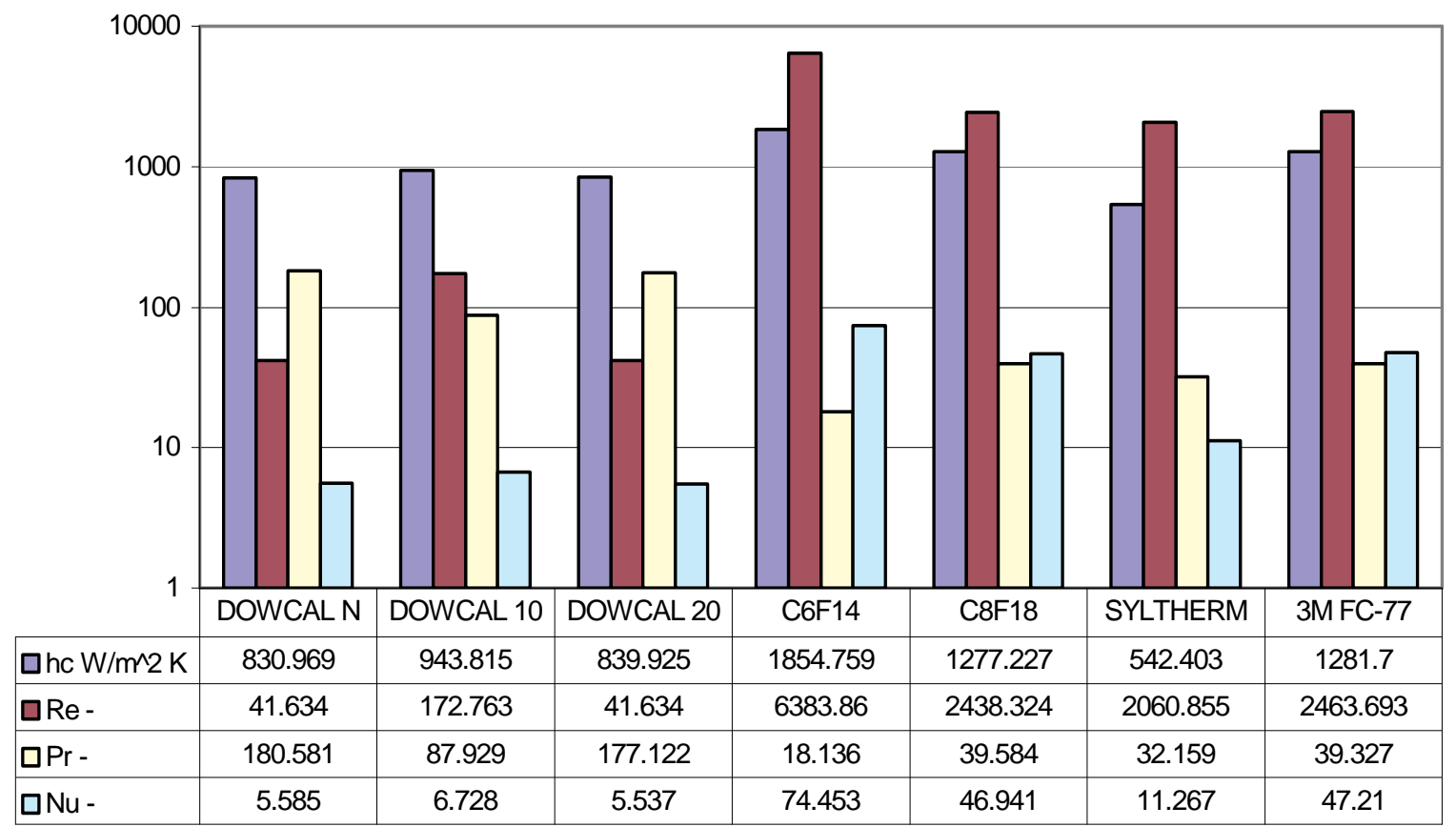

Figure 12 - Film coefficient (hc), Reynolds number (Re), Prandtl number (Pr) and Nusselt number (Nu) given the pressure drop along the pipe.

\subsection{The program for the coolant performance}

The fluid analyses were performed using MathCAD. For brevity only the program list related to the $\mathrm{C}_{6} \mathrm{~F}_{14}$ is reported. Analogous printouts are available for the other fluids studied.

The following analysis applies to a pipe with a rectangular section. Both the laminar and the turbulent flow are predicted.

\section{- Given Tb2}

$\mathrm{Tb}_{1}:=263 \cdot \mathrm{K}$

$\mathrm{Tb}_{2}:=265 \cdot \mathrm{K}$

average bulk temperature along the pipe

$\mathrm{Tb}:=\frac{\left(\mathrm{Tb}_{1}+\mathrm{Tb}_{2}\right)}{2}$

pipe length

$\mathrm{L}:=1.2 \cdot \mathrm{m}$ 
Fermi National Accelerator Laboratory

Giobatta Lanfranco Silicon Engineering Group - Mechanical Dep.

power to dissipate

$\mathrm{q}_{\mathrm{c}}:=100 \cdot \mathrm{W}$

pipe inner dimensions

$\mathrm{b}:=.23 \cdot$ in

$\mathrm{h}:=0.06 \cdot$ in

Geometric quantities

$\mathrm{A}_{\text {cross }}:=\mathrm{b} \cdot \mathrm{h}$

$\mathrm{p}:=2 \cdot(\mathrm{b}+\mathrm{h})$

$\mathrm{D}_{\mathrm{H}}:=4 \cdot \frac{\mathrm{A}_{\text {cross }}}{\mathrm{p}}$

Physical Properties

data $:=\left[\begin{array}{cc}-30 & 967.38 \\ -20 & 982.92 \\ -10 & 998.46 \\ 0 & 1014.0 \\ 10 & 1029.54 \\ 20 & 1045.08\end{array}\right]$

data $:=\operatorname{csort}($ data, 1$)$

$X:=$ data $^{<1>}$

$\mathrm{Y}:=$ data $^{<2>}$

$\mathrm{S}:=\operatorname{cspline}(\mathrm{X}, \mathrm{Y})$

$\mathrm{Cpp}(\mathrm{T}):=$ interp $\left[\mathrm{S}, \mathrm{X}, \mathrm{Y},\left(\frac{\mathrm{T}}{\mathrm{K}}-273\right)\right] \cdot \frac{\mathrm{joule}}{\mathrm{kg} \cdot \mathrm{K}}$

$\mathrm{Cp}:=\mathrm{Cpp}(\mathrm{Tb})$

data $:=\left[\begin{array}{cc}-30 & 0 \\ -20 & 0.0622 \\ -10 & 0.0611 \\ 0 & 0.06 \\ 10 & 0.0589 \\ 20 & 0.0578\end{array}\right]$

data $:=\operatorname{csort}($ data, 1$)$

$X:=$ data $^{<1>}$

$\mathrm{Y}:=$ data $^{<2>}$

$\mathrm{S}:=\operatorname{cspline}(\mathrm{X}, \mathrm{Y})$ 
Fermi National Accelerator Laboratory

Giobatta Lanfranco Silicon Engineering Group - Mechanical Dep.

$\operatorname{kk}(\mathrm{T}):=\operatorname{interp}\left[\mathrm{S}, \mathrm{X}, \mathrm{Y},\left(\frac{\mathrm{T}}{\mathrm{K}}-273\right)\right] \cdot \frac{\mathrm{W}}{\mathrm{m} \cdot \mathrm{K}}$

$\mathrm{k}:=\mathrm{kk}(\mathrm{Tb})$

data $:=\left[\begin{array}{cc}-30 & 1818.3 \\ -20 & 1792.20 \\ -10 & 1766.1 \\ 0 & 1740 \\ 10 & 1713.9 \\ 20 & 1687.8\end{array}\right]$

data $:=\operatorname{csort}($ data, 1$)$

$\mathrm{X}:=$ data $^{<1>}$

$\mathrm{Y}:=\operatorname{data}^{<2>}$

$\mathrm{S}:=\operatorname{cspline}(\mathrm{X}, \mathrm{Y})$

$\rho \rho(\mathrm{T}):=$ interp $\left[\mathrm{S}, \mathrm{X}, \mathrm{Y},\left(\frac{\mathrm{T}}{\mathrm{K}}-273\right)\right] \cdot \frac{\mathrm{kg}}{\mathrm{m}^{3}}$

$\rho:=\rho \rho(\mathrm{Tb})$

data $:=\left[\begin{array}{cc}-30 & 1.70078 \\ -20 & 1.37287 \\ -10 & 1.13034 \\ 0 & 0.94598 \\ 10 & 0.80293 \\ 20 & 0.69016\end{array}\right]$

data $:=\operatorname{csort}($ data, 1$)$

$\mathrm{X}:=$ data $^{<1>}$

$\mathrm{Y}:=\operatorname{data}^{<2>}$

$\mathrm{S}:=\operatorname{csplin}(\mathrm{X}, \mathrm{Y})$

$\mu \mu(\mathrm{T}):=\operatorname{interp}\left[\mathrm{S}, \mathrm{X}, \mathrm{Y},\left(\frac{\mathrm{T}}{\mathrm{K}}-273\right)\right] \cdot \frac{\text { poise }}{100}$

$\mu:=\mu \mu(\mathrm{Tb})$

$\mu=1.11 \cdot \frac{\text { poise }}{100}$

flow average velocity and mass rate

$\mathrm{U}:=1 \cdot \frac{\mathrm{m}}{\mathrm{s}}$

$\mathrm{U}:=\operatorname{root}\left[\left(\rho \cdot \mathrm{U} \cdot \mathrm{A}_{\text {cross }}\right) \cdot \mathrm{Cp} \cdot\left(\mathrm{Tb}_{2}-\mathrm{Tb}_{1}\right)-\mathrm{q}_{\mathrm{c}}, \mathrm{U}\right]$ 
Fermi National Accelerator Laboratory

Giobatta Lanfranco Silicon Engineering Group - Mechanical Dep.

$$
\begin{aligned}
& \mathrm{U}=3.185 \mathrm{~m} \cdot \frac{1}{\mathrm{~s}} \\
& \mathrm{M}:=\rho \cdot \mathrm{U} \cdot \mathrm{A}_{\text {cross }} \\
& \mathrm{M}=3 \mathrm{~kg} \cdot \frac{1}{\mathrm{~min}}
\end{aligned}
$$

Reynolds number, friction coefficient, Prandtl number, pressure loss

$$
\operatorname{Re}:=\rho \cdot U \cdot \frac{\mathrm{D}_{H}}{\mu}
$$

$\operatorname{Re}=12234.257$

f correction factor for laminar friction coefficient in presence of rectangular cross section

$$
\mathrm{fi}:=\left[\begin{array}{cc}
0 & 1.5 \\
0.1 & 1.34 \\
0.3 & 1.10 \\
0.5 & 0.97 \\
0.8 & 0.9 \\
1 & 0.88
\end{array}\right]
$$

fi $:=\operatorname{csort}(f i, 1)$

$X:=\mathrm{fi}^{<1>}$

$Y:=f^{<2>}$

$\mathrm{S}:=\operatorname{cspline}(\mathrm{X}, \mathrm{Y})$

$\phi(\mathrm{x}):=\operatorname{interp}(\mathrm{S}, \mathrm{X}, \mathrm{Y}, \mathrm{x})$

$\phi:=\phi\left(\frac{\mathbf{h}}{\mathbf{b}}\right)$

$\phi=1.138$

$$
f:=\mid \begin{aligned}
& {\left[\frac{0.3164}{(\operatorname{Re})^{0.25}}\right] \text { if }\left(2320<\operatorname{Re} \leq 10^{5}\right)} \\
& \left(0.184 \cdot \operatorname{Re}^{-0.2}\right) \text { if } 10^{5}<\operatorname{Re}<10^{6} \\
& \left(\phi \cdot \frac{64}{\operatorname{Re}}\right) \text { if } \operatorname{Re} \leq 2320 \\
& \left(0.032+0.221 \cdot \operatorname{Re}^{-0.237}\right) \text { otherwise }
\end{aligned}
$$

(Blasius)

$f=0.03$

$\mathrm{f}_{0}:=\mathrm{f}$ 
$\operatorname{Pr}:=\mathrm{Cp} \cdot \frac{\mu}{\mathrm{k}}$

$\operatorname{Pr}=18.318$

$\Delta \mathrm{p}:=\mathrm{f} \cdot \frac{\mathrm{L}}{\mathrm{D}_{\mathrm{H}}} \cdot \frac{1}{2} \cdot \rho \cdot \mathrm{U}^{2}$

$\Delta \mathrm{p}=19.368 \circ \mathrm{psi}$

Wall temperature

$\begin{aligned} & \mathrm{Nu}\left(\mathrm{T}_{\mathrm{w}}\right):= {\left[0.021 \cdot \mathrm{Re}^{0.8} \cdot \operatorname{Pr}^{0.4} \cdot\left(\frac{\mathrm{T}_{\mathrm{W}}}{\mathrm{Tb}}\right)^{-0.7} \cdot\left[1+\left(\frac{\mathrm{L}}{\mathrm{D}_{\mathrm{H}}}\right)^{-0.7} \cdot\left(\frac{\mathrm{T}_{\mathrm{W}}}{\mathrm{Tb}}\right)\right]\right] \text { if } \operatorname{Re}>2320 } \\ & {\left[1.86 \cdot\left(\frac{\operatorname{Re} \cdot \operatorname{Pr} \cdot \mathrm{D}_{\mathrm{H}}}{\mathrm{L}}\right)^{0.33} \cdot\left(\frac{\mu \mu(\mathrm{Tb})}{\mu \mu\left(\mathrm{T}_{\mathrm{w}}\right)}\right)\right] \text { otherwise } }\end{aligned}$

$\mathrm{hc}\left(\mathrm{T}_{\mathrm{w}}\right):=\mathrm{k} \cdot \frac{\mathrm{Nu}\left(\mathrm{T}_{\mathrm{w}}\right)}{\mathrm{D}_{\mathrm{H}}}$

$\mathrm{T}_{\mathrm{W}}:=273 \cdot \mathrm{K}$

$\mathrm{T}_{\text {wall }}:=\operatorname{root}\left[\left[\mathrm{hc}\left(\mathrm{T}_{\mathrm{w}}\right) \cdot \mathrm{p} \cdot \mathrm{L} \cdot\left(\mathrm{T}_{\mathrm{w}}-\mathrm{Tb}\right)-\mathrm{q}_{\mathrm{c}}\right], \mathrm{T}_{\mathrm{w}}\right]$

$\mathrm{T}_{\text {wall }}=265.789 \mathrm{~K}$

$\mathrm{Tb}_{1}=263 \mathrm{~K}$

$\mathrm{Tb}_{2}=265 \mathrm{~K}$

$\mathrm{hc}\left(\mathrm{T}_{\text {wall }}\right)=3162.169 \frac{1}{\mathrm{~m}^{2} \cdot \mathrm{K}} \cdot \mathrm{W}$

$\mathrm{Nu}\left(\mathrm{T}_{\text {wall }}\right)=126.186$ 
Fermi National Accelerator Laboratory

Giobatta Lanfranco Silicon Engineering Group - Mechanical Dep.

\section{- Given $\Delta \mathbf{p}$}

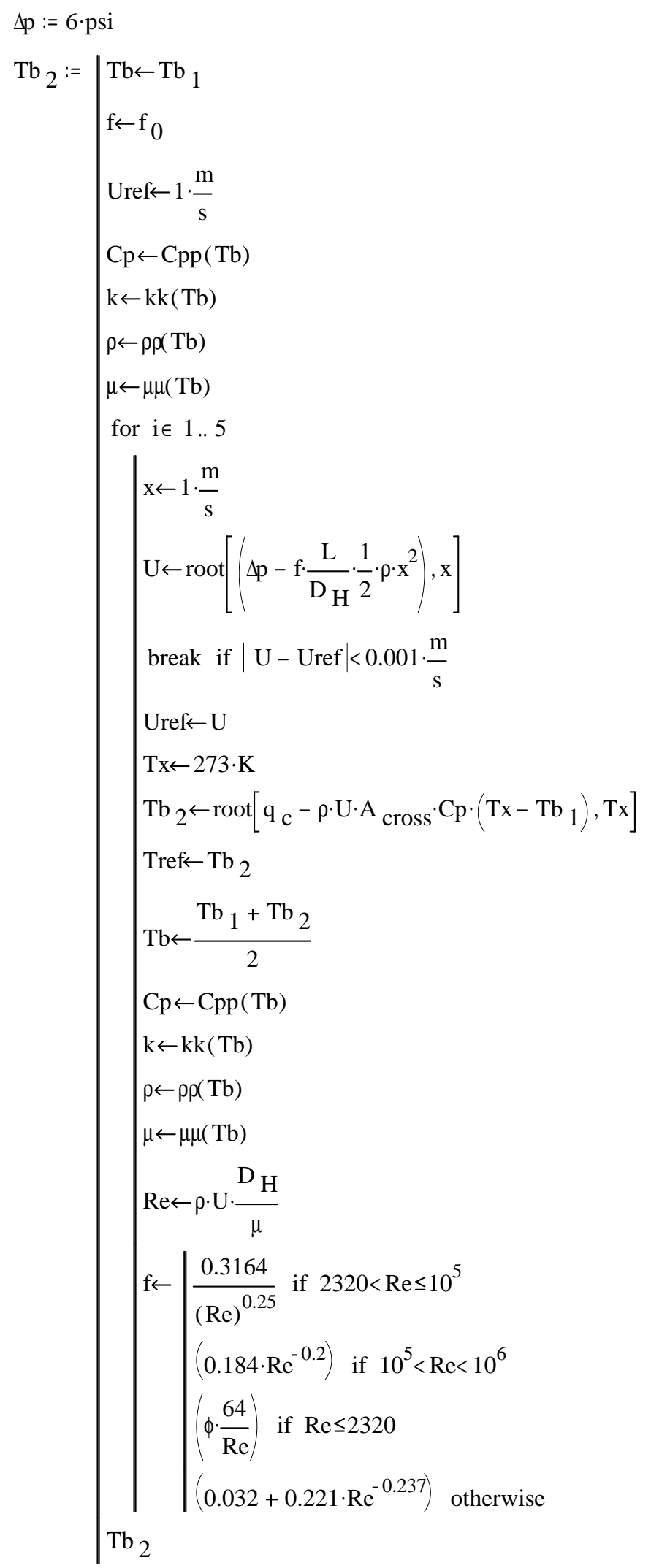


Fermi National Accelerator Laboratory

Giobatta Lanfranco Silicon Engineering Group - Mechanical Dep.

$\mathrm{Tb}_{2}=266.894 \mathrm{~K}$

$\mathrm{Tb}:=\frac{\left(\mathrm{Tb}_{1}+\mathrm{Tb}_{2}\right)}{2}$

$\mathrm{Cp}:=\mathrm{Cpp}(\mathrm{Tb})$

$\mathrm{k}:=\mathrm{kk}(\mathrm{Tb})$

$\rho:=\rho \rho(\mathrm{Tb})$

$\mu:=\mu \mu(\mathrm{Tb})$

$\mathrm{U}:=\operatorname{root}\left[\mathrm{q}_{\mathrm{c}}-\rho \cdot \mathrm{U} \cdot \mathrm{A}_{\mathrm{cross}} \cdot \mathrm{Cp} \cdot\left(\mathrm{Tb}_{2}-\mathrm{Tb} \mathrm{b}_{1}\right), \mathrm{U}\right]$

$\mathrm{U}=1.635 \frac{\mathrm{m}}{\mathrm{s}}$

$\mathrm{M}:=\rho \cdot \mathrm{U} \cdot \mathrm{A}_{\text {cross }}$

$\mathrm{M}=1.538 \mathrm{~kg} \circ \frac{1}{\mathrm{~min}}$

$\operatorname{Pr}:=\mathrm{Cp} \cdot \frac{\mu}{\mathrm{k}}$

$\operatorname{Re}:=\rho \cdot U \cdot \frac{\mathrm{D}_{H}}{\mu}$

$\operatorname{Re}=6383.86$

$\operatorname{Pr}=18.136$

Wall temperature

$\begin{aligned} & \mathrm{Nu}\left(\mathrm{T}_{\mathrm{W}}\right):= {\left[0.021 \cdot \operatorname{Re}^{0.8} \cdot \operatorname{Pr}^{0.4} \cdot\left(\frac{\mathrm{T}_{\mathrm{W}}}{\mathrm{Tb}}\right)^{-0.7} \cdot\left[1+\left(\frac{\mathrm{L}}{\mathrm{D}_{\mathrm{H}}}\right)^{-0.7} \cdot\left(\frac{\mathrm{T}_{\mathrm{W}}}{\mathrm{Tb}}\right)\right]\right] \text { if } \operatorname{Re}>2320 } \\ & {\left[1.86 \cdot\left(\frac{\operatorname{Re} \cdot \operatorname{Pr} \cdot \mathrm{D}_{\mathrm{H}}}{\mathrm{L}}\right)^{0.33} \cdot\left(\frac{\mu \mu(\mathrm{Tb})}{\mu \mu\left(\mathrm{T}_{\mathrm{w}}\right)}\right)\right] \text { otherwise } }\end{aligned}$

Perkins (turbulent)

$\mathrm{hc}\left(\mathrm{T}_{\mathrm{w}}\right):=\mathrm{k} \cdot \frac{\mathrm{Nu}\left(\mathrm{T}_{\mathrm{w}}\right)}{\mathrm{D}_{\mathrm{H}}}$

$\mathrm{T}_{\mathrm{W}}:=273 \cdot \mathrm{K}$

$\mathrm{T}_{\text {wall }}:=\operatorname{root}\left[\left[\mathrm{hc}\left(\mathrm{T}_{\mathrm{w}}\right) \cdot \mathrm{p} \cdot \mathrm{L} \cdot\left(\mathrm{T}_{\mathrm{w}}-\mathrm{Tb}\right)-\mathrm{q}_{\mathrm{c}}\right], \mathrm{T}_{\mathrm{w}}\right]$

$\mathrm{T}_{\text {wall }}=267.997 \mathrm{~K}$

$\mathrm{Tb}_{1}=263 \mathrm{~K}$

Sieder-Tate (laminar) 
Fermi National Accelerator Laboratory

Giobatta Lanfranco Silicon Engineering Group - Mechanical Dep.

$\mathrm{Tb}=264.947 \mathrm{~K}$

$\mathrm{Tb}_{2}=266.894 \mathrm{~K}$

$\mathrm{hc}\left(\mathrm{T}_{\text {wall }}\right)=1854.759 \frac{1}{\mathrm{~m}^{2} \cdot \mathrm{K}} \cdot \mathrm{W}$

$\mathrm{Nu}\left(\mathrm{T}_{\text {wall }}\right)=74.453$

\section{References}

1. «Radiation Hardness Studies of Cooling Fluids. Epoxies and Capacitors for CMS Pixel System», M.Atac, B.Gobbi, L.Cremaldi, J.Hoffman

2. «Principles of Heat Transfer», F.Kreith, M.S.Bohn, $6^{\text {th }}$ ed., Brooks/Cole

3. «Handbook of Mechanical Engineering», H.Dubbel, Hardcover, Springer-Verlag New York, Incorporated, November 1994 